\title{
Influence of isothermal and cyclic heat treatments on the adhesion of plasma sprayed thermal barrier coatings
}

Robert Eriksson, Håkan Brodin, Sten Johansson, Lars Östergren and Xin-Hai Li

\section{Linköping University Post Print}

N.B.: When citing this work, cite the original article.

Original Publication:

Robert Eriksson, Håkan Brodin, Sten Johansson, Lars Östergren and Xin-Hai Li, Influence of isothermal and cyclic heat treatments on the adhesion of plasma sprayed thermal barrier coatings, 2011, Surface \&amp; Coatings Technology, (205), 23-24, 5422-5429.

http://dx.doi.org/10.1016/j.surfcoat.2011.06.007

Copyright: Elsevier http://www.elsevier.com/

Postprint available at: Linköping University Electronic Press http://urn.kb.se/resolve?urn=urn:nbn:se:liu:diva-67882 


\title{
Influence of isothermal and cyclic heat treatments on the adhesion of plasma sprayed thermal barrier coatings
}

\author{
Robert Eriksson ${ }^{\mathrm{a}, *}$, Håkan Brodinn ${ }^{\mathrm{b}, \mathrm{a}}$, Sten Johansson ${ }^{\mathrm{a}}$, Lars Östergren ${ }^{\mathrm{c}}$, \\ Xin-Hai $\mathrm{Li}^{\mathrm{b}}$ \\ ${ }^{a}$ Division of Engineering Materials, Department of Management and Engineering, \\ Linköpings universitet, SE-58183 Linköping, Sweden \\ ${ }^{b}$ Siemens Industrial Turbomachinery AB, SE-61283 Finspång, Sweden \\ ${ }^{c}$ Volvo Aero Corporation, SE-46181 Trollhättan, Sweden
}

\begin{abstract}
The adhesion of thermal barrier coatings (TBC) has been studied using the standard method described in ASTM C633, which makes use of a tensile test machine to measure the adhesion. The studied specimens consist of air plasma sprayed (APS) TBC deposited on disc-shaped substrate coupons of Ni-base alloy Hastelloy X. The bond coat (BC) is of a NiCoCrAlY type and the top coat (TC) consists of yttria-stabilised-zirconia. Before the adhesion test, the specimens were subjected to three different heat treatments: 1) isothermal oxidation at $1100^{\circ} \mathrm{C}$ up to $\left.290 \mathrm{~h}, 2\right)$ thermal cycling fatigue $(\mathrm{TCF})$ at $1100^{\circ} \mathrm{C}$ up to 300 cycles and 3 ) thermal shock at $\sim 1140{ }^{\circ} \mathrm{C} \mathrm{BC} / \mathrm{TC}$ interface temperature up to 1150 cycles. The adhesion of the specimens is reported and accompanied by a microstructural study of the $\mathrm{BC}$ and the thermally grown oxides (TGO), as well as a discussion on the influence of $\mathrm{BC} / \mathrm{TC}$ interfacial damage on adhesion properties of TBC. The adhesion was
\end{abstract}

*Corresponding author. Tel.: +46 13 284410; fax: +46 13 282505. E-mail address: robert.eriksson@liu.se 
found to vary with heat treatment, as well as with heat treatment length. Keywords: thermal barrier coating, TBC, adhesion, thermal cycling fatigue, thermal shock, burner rig test

\section{Introduction}

Due to the increased fuel efficiency that can be achieved by increasing combustion temperature, the development of gas turbines has inevitably led to increased service temperatures, [1]. However, the subsequent severity of high temperature phenomena, such as rapid oxidation and loss in mechanical properties, significantly lowers the service life of metallic components and must therefore be avoided. Thermal barrier coatings (TBCs) are frequently used in gas turbines to reduce such high temperature degradation by providing insulation, hence lowering the temperature of the metal substrate, $[2-5]$.

Thermal barrier coatings consist of a ceramic top coat (TC), which provides the necessary insulation, and a metallic bond coat (BC) to improve bonding and oxidation resistance. The TC typically consists of $6-8 \% \mathrm{Y}_{2} \mathrm{O}_{3}-$ stabilised $-\mathrm{ZrO}_{2}$ and the $\mathrm{BC}$ usually consists of MCrAlY where $\mathrm{M}$ is metals such as Ni, Co and, for some applications, Fe, [4, 6].

A common method for deposition of TBCs is air plasma spraying (APS), [1], which provides high enough temperatures to melt the $\mathrm{ZrO}_{2}$. The raw material, in powder form, is fed into a plasma flame which melts the powder into droplets and accelerates them towards the substrate. The TBC is formed as the splats formed on impact with the substrate build up. The BC can, in addition to APS, also be deposited by vacuum plasma spraying, [1, 7, 8]. 
During high temperature exposure the $\mathrm{BC}$ will oxidise and form thermally grown oxides (TGOs), predominantly in the $\mathrm{BC} / \mathrm{TC}$ interface but also within the $\mathrm{BC}$. The growth of the $\mathrm{BC} / \mathrm{TC}$ interfacial TGO typically follows a powerlaw expression, $[9,10]$ :

$$
h_{\mathrm{TGO}}=K t^{\frac{1}{n}}, n=2-3
$$

where $h_{\mathrm{TGO}}$ is the TGO thickness as function of time, $t$, and $K$ is the oxide growth rate constant.

$\mathrm{Al}$ is present as alloying element in $\mathrm{BCs}$, predominantly bound in the $\beta$-NiAl phase, [11-13], to promote the formation of a protective layer of $\mathrm{BC} / \mathrm{TC}$ interface alumina, $\mathrm{Al}_{2} \mathrm{O}_{3}$. The protective $\mathrm{Al}_{2} \mathrm{O}_{3}$ layer will prevail as long as there is enough $\mathrm{Al}$ left in the $\mathrm{BC}$ to maintain the $\mathrm{Al}_{2} \mathrm{O}_{3}$ layer by suppressing the formation of non-protective oxides, [14-16]. As $\mathrm{Al}$ is consumed by the growing TGO and interdiffusion with the substrate, the Alrich phase $\beta$-NiAl will dissolve, [17]; this change in microstructure is referred to as $\beta$-phase depletion. The depletion of $\mathrm{Al}$ eventually causes breakdown of the protective layer of interface TGOs since non-protective oxides, such as chromia $(\mathrm{Cr}, \mathrm{Al})_{2} \mathrm{O}_{3}$ and spinels $(\mathrm{Ni}, \mathrm{Co})(\mathrm{Al}, \mathrm{Cr})_{2} \mathrm{O}_{4}$, will form, [18-21]. Such non-protective oxides are generally considered detrimental for the life of TBCs, [21-23].

TBC systems exposed to thermal cycling will also degrade due to fatigue. Fatigue cracks grow due to thermal stresses introduced by differences in the coefficient of thermal expansion between the metallic BC and ceramic TC, [24]. Fatigue degradation of TBCs is often thought to occur by the simultaneous growth of many microcracks, preferably at the BC/TC interface, [25], and thus influenced by the stresses introduced by the growing interface TGO, 
[24]. The final failure occurs by large-scale coalescence of many microcracks which causes the TC to delaminate and eventually to spall off, [21, 22, 26]. Failures that reveal the interface TGO or BC will appear dark to the eye and are referred to as black fracture. In analogy, failures that occur in the TC are referred to as white fracture, [21]. Fracture surfaces may also display a mixed-type fracture where both types of fracture mechanism, black and white, are present.

Several methods are available for evaluating the adhesion of TBCs, [2733]. One of them, and the one of concern in the present study, is the tensile adhesion test (TAT) described in ASTM C633, according to which one uses a common tensile test machine to measure the adhesive strength of a TBC system. Previous tensile adhesion tests of APS and high-velocity oxyfuel sprayed TBC systems have shown that TBC systems mainly fracture close to the $\mathrm{BC} / \mathrm{TC}$ interface and give adhesion strengths of 10-50 MPa, [3437]. Fracture toughness measurement by Vickers indentation has also been shown applicable to coatings, [27, 36, 38, 39], and a correlation has been found between tensile adhesion strength and interface indentation toughness, $[27,36]$. Tensile adhesion of heat treated coatings has been somewhat studied, [31, 34, 39, 40]: TBC systems exposed to short, $(2 \mathrm{~h})$, heat treatments exhibited an increase in adhesion strength, [34], while thermal cycling decreased the adhesion strength, [40]. While some work has been done, no extensive study has so far been done on the influence of various heat treatments on the tensile adhesion of TBC systems. In the present study, adhesion tests have been conducted on as-sprayed and heat treated TBC coatings deposited on Ni-base substrates. Three different heat treatments have been used and a 
comparison has been made between their corresponding adhesion strengths. Furthermore, the microstructural degradation and oxidation behaviour has been characterised for the different heat treatments.

\section{Experimental}

\subsection{Material}

The specimens in the present study consist of TBC deposited on substrates of the Ni-base alloy Hastelloy X, which has composition: $\mathrm{Ni}-22 \mathrm{Cr}-$ $18 \mathrm{Fe}-9 \mathrm{Mo}-1.5 \mathrm{Co}-0.6 \mathrm{~W}$, all in wt.\%, with additions of $\leqslant 1$ wt. $\% \mathrm{Mn}, \mathrm{C}$ and Si and minor additions of B. The substrate material was cut out of bar material giving disc-shaped specimens with a diameter of $25.4 \mathrm{~mm}$ and a thickness of $5-6.35 \mathrm{~mm}$, Table 1 . The substrate discs were grit blasted with alumina grit and APS coated with $150 \mu \mathrm{m}$ of $\mathrm{Ni}-23 \mathrm{Co}-17 \mathrm{Cr}-12.5 \mathrm{Al}-0.45 \mathrm{Y}$, all in wt. $\%$, and $300 \mu \mathrm{m}$ of $7 \mathrm{wt} . \%$ yttria-stabilised-zirconia using equipment from Sulzer Metco.

\subsection{Heat treatment}

The specimens where subjected to three different heat treatments: 1) isothermal oxidation, 2) thermal cycling fatigue (TCF) (performed at Siemens Industrial Turbomachinery) and 3) burner rig test (BRT) using a thermal shock rig (TSR) (performed at Volvo Aero Corporation). The heat treatments were performed for varying lengths of time as summarised in Table 1.

The isothermal oxidation was conducted at $1100^{\circ} \mathrm{C}$ at atmospheric conditions for times up to $290 \mathrm{~h}$. When removed from the furnace, the specimens were left to cool in air. 
Thermal cycling fatigue involves placing the specimens on a palette which is moved in and out of a furnace, thus cycling between high and low temperatures. One cycle consist of high temperature exposure at $1100^{\circ} \mathrm{C}$ for $60 \mathrm{~min}$. The specimens are then moved out of the furnace and cooled by compressed air for $10 \mathrm{~min}$ thereby reaching a minimum temperature of $100^{\circ} \mathrm{C}$. Of the $60 \mathrm{~min}$ high temperature exposure, approximately $6 \mathrm{~min}$ are required to reach maximum temperature.

The thermal shock rig is used to test the thermal shock resistance of coated specimens. A cycle consists of $75 \mathrm{~s}$ heating followed by $75 \mathrm{~s}$ of cooling. The heating is done on the coated side of the specimen with propane burners while, at the same time, cooling the specimen at the uncoated side by air, hence introducing a temperature gradient in the specimen. During cooling the specimen is moved out of the propane flame and cooled on the uncoated side by air. During heating, the temperatures on the coated and uncoated sides reach $1250^{\circ} \mathrm{C}$ and $950^{\circ} \mathrm{C}$ respectively. The temperature is measured with pyrometers. The transparency of the zirconia coating is accounted for by adjusting for the emissivity of both the topcoat and the bondcoat/substrate and the transmissivity of the topcoat so that the pyrometer is not 'looking through' the top layer and measuring the bond coat/substrate temperature. A steady-state thermal analysis, using finite element software and thermal conductivity data from Ref. [41], predicts that the BC temperature will be approximately $1140^{\circ} \mathrm{C}$. The rig is further described in Ref. [42] and a temperature curve for a similar cycle is available in Ref. [43]. 


\subsection{Adhesion test}

The heat-treated specimens were subjected to adhesion tests using ASTM C633 Standard Test Method for Adhesion or Cohesion Strength of Thermal Spray Coatings. The method involves fastening the specimen to two rods using FM1000 epoxy adhesive, enabling the specimen to be mounted in a tensile test machine equipped with universal joints. The specimen was loaded until fracture and the corresponding fracture stress was recorded. The number of specimens used is shown in Table 1. Further details regarding the test method can be found in the ASTM standard, [44].

\subsection{Specimen preparation and microscopy}

From each of the heat treatments, two specimens were cross-sectioned and mounted for microscopy: one as-is and one adhesion-tested (i.e. the resulting fracture surface from the adhesion test). The specimens were epoxy infiltrated in vacuum, hot mounted and then ground with diamond abrasives down to $1 \mu \mathrm{m}$ and polished using alumina dispersion.

For each of the three heat treatments, the interface TGO thickness was measured in light optical microscope (LOM). The thickness of the oxide layer was measured at 100 equidistant points distributed over the length of the cross-section; the thickness was measured between the BC/TGO interface and the TGO/TC interface hence including all present oxides in the measurement, regardless of whether the oxide was a smooth layer or a bulky oxide cluster. The oxide thickness has been measured perpendicular to the $\mathrm{BC} / \mathrm{TGO}$ interface.

After the adhesion test, some residual TC still remains on the substrate side of the fracture surface. The cross-sectioned fracture surfaces were used 
to measure the thickness of the residual TC on the substrate side of the fracture surface. The measurement was performed in the same way as the TGO thickness measurement.

The compositions of the BC and the substrate were measured by energy dispersive spectroscopy (EDS) at a large number of points distributed along a line starting from the $\mathrm{BC} / \mathrm{TC}$ interface stretching down through the $\mathrm{BC}$, ending $150 \mu \mathrm{m}$ below the $\mathrm{BC} /$ substrate interface. The weight percentage of alloying elements was recorded as a function of the distance from $\mathrm{BC} / \mathrm{TC}$ interface.

The fracture surfaces resulting from the adhesion test were also analysed in scanning electron microscope (SEM). The amount of black fracture was measured using EDS mapping. For each specimen 181.30 x $0.98 \mathrm{~mm}$ maps were established for $\mathrm{Ni}, \mathrm{Co}, \mathrm{Cr}, \mathrm{Al}$, and $\mathrm{Zr}$. The area fraction of $\mathrm{Zr}$ corresponds to white fracture and the combined area fractions of $\mathrm{Ni}, \mathrm{Co}, \mathrm{Cr}$ and $\mathrm{Al}$ corresponds to black fracture. The measured area fractions have been normalized so that the area fraction of white and black fracture add up to $100 \%$. Prior to normalisation, the sum of black and white fracture is typically $70-80 \%$ due to X-ray shadows caused by the rough surface.

Microscopy studies were performed with a Nikon optiphot LOM and a FEG-SEM Hitachi SU-70 equipped with an EDS detector from Oxford Instruments. Before analysis in SEM, the specimens were coated with approximately $25 \mathrm{~nm}$ of carbon. 


\section{Results}

\subsection{Microstructural development and TGO formation}

The as-sprayed BC microstructure consists of rapidly solidified splats in which the occurrence of $\beta$-phase is sparse; the formation of the $\beta$-NiAl occurs as soon the specimens are exposed to high temperature. For the relatively short high temperature exposure times associated with BRT, $\beta$ remains one of the main microconstituents throughout the cycling; Fig. 1 a) shows extensive $\beta$ content in BRT subjected specimens. For BRT 1150 cycles, Fig. 1 b), minor $\beta$-phase depletion has taken place at the outermost parts of the $\mathrm{BC}$; the $\beta$-phase has also coarsened slightly. BRT, in contrast to TCF, tends to open up the splat-on-splat structure in the $\mathrm{BC}$, increasing the inter-splat delamination, Fig. 2.

Also displayed in Fig. 1 is the microstructure of the isothermally oxidized specimens. For $1 \mathrm{~h}$ of high temperature exposure, Fig. $1 \mathrm{c}$ ), the microstructure consists of large amount of $\beta$-phase, as for the BRT subjected specimens. For $23 \mathrm{~h}$ of high temperature exposure, Fig. $1 \mathrm{~d}$ ), the $\beta$-phase depletion has already advanced so far that no $\beta$ can be observed in the top and bottom regions of the $\mathrm{BC} ; 47 \mathrm{~h}$ of high temperature exposure further decreases the amount of $\beta$ and at $111 \mathrm{~h}$ the $\beta$-phase is essentially gone.

Fig. 3 a) shows the interdiffusion of $\mathrm{Co}, \mathrm{Fe}$ and Mo between the substrate and bond coat; 1150 cycles of BRT can be seen to give less interdiffusion than 24 cycles of TCF. Fig. 3 b) shows the substrate/BC interdiffusion of $\mathrm{Al}$, (internal oxides in the $\mathrm{BC}$ have been identified by their corresponding oxygen peaks in the EDS data and have been removed from Fig. 3 b), i.e. Fig. 3 b) only shows metallic Al). For 1150 cycles of BRT, the interdiffusion 
of $\mathrm{Al}$ is quite modest.

The oxidation rate and oxide composition is quite similar for TCF and isothermal oxidation. The main oxide to form is a continuous layer of essentially pure alumina, occasionally crowned with Cr-rich oxides or spangled with yttrium-rich oxides; bulky clusters of oxides, as shown in Fig. 4 a) and b), occurs sparingly in the BC/TC interface. Specimens subjected to BRT typically give a thin layer of relatively pure alumina; bulky oxide clusters are very rare, even for 1150 cycles.

The interface TGO thickness for isothermal oxidation and TCF, as a function of high temperature exposure time, is shown in Fig. 5 a), which also displays curve fits using Eq. 1 with $n=3$. Fig. 5 b) shows the interface TGO thickness for BRT and TCF subjected specimens as a function of cycles; due to shorter high-temperature exposure, BRT gives thinner interface TGO than TCF. The error bars in Fig. 5 show one standard deviation, the large scatter is due to voluminous oxides such as Cr-, Ni- and spinel type oxides, which are included in the TGO thickness measurement, (as explained in section 2.4).

\subsection{Adhesion of $T B C$}

The adhesion of the TC has been found to vary with high temperature exposure time and number of cycles. The change in adhesion as a function of interface TGO thickness is displayed in Fig. 6 b). (The adhesion has been plotted versus TGO thickness out of necessity, since the total hightemperature exposure time for BRT cannot be accurately estimated. The TGO thickness may, in this context, be thought of as describing cumulative high temperature exposure time.) Compared to the as-sprayed condition, isothermally heat treating the coupons for a short period of time increases 
the adhesion. As seen in Fig. 6 a), isothermal heat treatment for $1 \mathrm{~h}$ only gives a modest increase in adhesion compared to the as-sprayed condition, whereas $23 \mathrm{~h}$ gives an increase of about $50 \%$.

TCF initially also increases the adhesion compared to the as-sprayed specimen, Fig. 6 b), but for continuing cycling the adhesion decreases. As the interface TGO thickens the two cyclic heat treatments both lower the adhesion, BRT more severely than TCF, whereas it remains essentially constant, or even increases slightly, for isothermal oxidation, Fig. 6 b). Fig. 7 shows the adhesion versus number of cycles, (isothermal oxidation is considered to consist of one cycle). The figure shows a tendency for decreasing adhesion with increasing number of cycles, regardless of testing method.

\subsubsection{Damage development during cycling}

The TCF subjected specimens display increasing interface damage as the interface TGO thickens. At some locations, preferably at peaks in the $\mathrm{BC} / \mathrm{TC}$ interface, the TGO has undergone extensive cracking by several parallel horizontal cracks thus layering the TGO, shown in Fig 8 a). Furthermore, cracks can be seen to run parallel to the BC/TC interface, either entirely in the TGO or, more often, partly in the TGO and partly in the TC, as seen in Fig 8 a).

The specimens subjected to BRT differ from the TCF subjected specimens by their low amount of quantifiable damage. At the BC/TC interface, damage can hardly be seen at all, except for some sparingly occurring voids between the TGO and the TC. The interface TGO thickness is very low for BRT specimens and no cracked TGO exists at all. Some horizontal cracks can be seen in the TC, Fig. 8 b); in this aspect they do, however, not differ sig- 
nificantly from the TCF subjected specimen in which similar TC inter-splat delaminations can be found.

\section{Discussion}

\subsection{Microstructural development and TGO formation}

For BRT the high temperature exposure time is to short to cause any severe microstructural degradation. Even for 1150, the presence of $\beta$-phase is abundant, the interface TGO is thin and Fig. 3 b) shows that interdiffusion of $\mathrm{Al}$ is very low, even though the substrate material has a low aluminium content which promotes interdiffusion. For TCF, Al depletion due to oxidation and interdiffusion is clearly seen as $\beta$-phase depletion, Fig. 1 d), thick interface TGO, and interdiffusion with the substrate, Fig. 3 b). However, the EDS data in Fig. 3 b) shows that the Al content remains above the critical 3-5 wt. $\%$ below which a protective $\mathrm{Al}_{2} \mathrm{O}_{3}$-layer cannot be maintained, $[16,45]$.

The main difference in interface TGO between the heat treatments is the occurrence of bulky oxide clusters, shown in Fig. 4 a) and b): in the case of isothermal oxidation and TCF, such bulky oxide clusters are rather common, whereas they are very uncommon in the case of BRT. These clusters contain various kinds of oxides such as $\mathrm{Al}_{2} \mathrm{O}_{3},(\mathrm{Cr}, \mathrm{Al})_{2} \mathrm{O}_{3}, \mathrm{NiO}$ and $(\mathrm{Ni}, \mathrm{Co})(\mathrm{Al}, \mathrm{Cr})_{2} \mathrm{O}_{4},[46-50]$, and have been shown to be able to act as crack nucleation sites, [23, 47]. Fig. 4 a) shows such a cluster which still contains unoxidised metal, and Fig. 4 b) shows a cluster with a $\mathrm{NiO}$ core. Such oxide clusters do not necessarily depend on $\mathrm{Al}$ depletion to form, as they may very well form early during high temperature exposure from BC particles sticking 
out in the TC. Such particles, being nearly cut off from the BC, soon run out of $\mathrm{Al}$ and start forming $\mathrm{Cr}$ - and Ni-rich oxides well before the $\mathrm{Al}$ depletion has occurred in the underlying BC.

\subsection{Adhesion of TBC and fracture surface characteristics}

Even though extensive TGO growth might be considered detrimental to TBC adhesion, it is clear that the increase in interface TGO thickness alone does not explain the lowering of fracture stress as BRT, which has the lowest TGO growth rate, also has the lowest adhesion. The decrease in adhesion is attributed to the introduction of damage in the $\mathrm{TC}$ and $\mathrm{BC} / \mathrm{TC}$ interface during cycling, [40]. BRT gives the lowest adhesion values at a given TGO thickness as it is exposed to a larger number of cycles per $\mu \mathrm{m}$ of developed TGO. BRT, however, gives a slower decrease in adhesion per cycle: $\sim 1.5$. $10^{-3} \mathrm{MPa} /$ cycle for BRT, compared to $\sim 20 \cdot 10^{-3} \mathrm{MPa} /$ cycle for TCF.

The modest increase of adhesion, Fig. 6 a), for $1 \mathrm{~h}$ of isothermal oxidation is taken as an indication that the decrease of residual stresses, (that is likely to occur for $1 \mathrm{~h}$ at $\left.1100{ }^{\circ} \mathrm{C},[39]\right)$, does not, alone, explain the increase in tensile adhesion. It is rather the development of a thin alumina interface TGO that gives an increase in adhesion for these specimens, [34, 39, 51-54]. The slight increase in adhesion that occurs for further isothermal oxidation is likely due to sintering.

The fracture surfaces from the adhesion test have been characterised by two parameters: fraction black fracture and the height of the residual TC remaining on the $\mathrm{BC}$ after adhesion test, see Fig. 9, the results are reported in Table 2. The isothermal heat treatment typically gives large amount of white fracture, ( $\lesssim 4 \%$ black fracture), as does TCF up to 48 cycles; at 300 
cycles TCF gives $\sim 15 \%$ black fracture, Table 2 and Fig. 10 a). This transition of fracture mechanism from mainly TC fracture to increasing fractions of interface fracture is most likely due to an increase in interfacial damage. The increasing amount of voluminous non-protective oxides could also decrease the $\mathrm{BC} / \mathrm{TC}$ interface strength. However, the increase in interface TGO thickness alone does not cause a transition from white to black fracture as demonstrated by the isothermal oxidation which gives predominantly white fracture for all times.

Increasing amount of black fracture with number of cycles can also be seen for BRT where the amount of black fracture increases with number of cycles resulting in $\sim 7 \%$ and $\sim 15 \%$ black fracture for 300 and 1150 cycles respectively, Table 2 and Fig. 10 a). The specimens subjected to BRT are exposed to a somewhat higher peak temperature, (particularly the top coat), and higher cooling rates, which may introduce damage in the TBC system even though the TGO thickness remains small throughout the testing. It should be noted that 300 cycles of TCF is approximately half the expected life for this TBC, as is 1150 cycles in the case of BRT. Comparing 300 cycles of TCF with 1150 cycles of BRT one finds that the amount of black fracture is roughly the same.

Fig. $10 \mathrm{~b}$ ) shows that as the specimens are subjected to more and more thermal cycles, the white part of the fracture occurs closer and closer to the $\mathrm{BC} / \mathrm{TC}$ interface. It is also evident from Fig. $10 \mathrm{~b}$ ) that high adhesion is associated with larger amounts of residual TC, that is, the fracture occurs farther away from the BC/TC interface. Interestingly, even for TCF 300 cycles, which gives a relatively large amount of interfacial damage, the fracture 
may still occur in the TC rather then in the BC/TC interface; Fig. 9 shows an area where the fracture, despite extensive BC/TC interfacial damage, has occurred in the $\mathrm{TC}$ some $50 \mu \mathrm{m}$ from the $\mathrm{BC} / \mathrm{TC}$ interface.

Cross-sections of thermally cycled specimens reveal that TCF and BRT differ in that TCF gives much more BC/TC interface damage, shown in Fig 8 a), [22, 48]. As reported by [26, 43], thermal shock testing generally results in white fracture; the lack of detectable interfacial damage in BRT-subjected specimens conforms to that. Furthermore, the adhesion of isothermally oxidized specimens reveal that an interface TGO thickness of several $\mu \mathrm{m}$ may still be beneficial to the adhesion of TBC since it gives white fracture.

\section{Conclusions}

Air plasma sprayed thermal barrier coatings have been subjected to isothermal and cyclic heat treatments. The heat treated specimens have been adhesion tested and the damage, both introduced by adhesion test and heat treatment, have been characterized.

Specimen subjected to TCF and isothermal oxidation give very similar interface TGO thickness and TGO composition: a continuous layer of $\mathrm{Al}_{2} \mathrm{O}_{3}$ with occasional bulky oxide clusters of Cr-rich oxides, such as $(\mathrm{Cr}, \mathrm{Al})_{2} \mathrm{O}_{3}$ and spinels, and $\mathrm{NiO}$. The specimens subjected to BRT give much thinner interface TGO due to their shorter high temperature exposure time, and the TGO consists almost exclusively of $\mathrm{Al}_{2} \mathrm{O}_{3}$. Furthermore, TCF-subjected specimens have areas of cracked interface TGO while the thin interface TGO in the BRT-subjected specimens does not contain any cracks. 
The heat treatment and subsequent adhesion tests of TBC specimens have revealed that heat treatment influences the adhesion of TBCs. Isothermal oxidation up to $290 \mathrm{~h}$ has been shown to have a beneficial effect on adhesion compared to the as-sprayed condition, while cyclic heat treatment has been shown to decrease adhesion.

The decrease in adhesion is, in the case of TCF, attributed to the extensive cracking of the interface TGO and nearby TC, thus lowering adhesion by introducing damage. For BRT, damage introduced during cycling is not easily quantifiable for the range of cycling used here. The cause for the decrease in adhesion of BRT subjected TBC is yet to be understood.

\section{Acknowledgement}

This research has been funded by the Swedish Energy Agency, Siemens Industrial Turbomachinery AB, Volvo Aero Corporation, and the Royal Institute of Technology through the Swedish research programme TURBO POWER, the support of which is gratefully acknowledged. The authors would also like to accentuate the contribution of Professor Sören Sjöström who participates in the ongoing TBC research at Linköpings universitet.

\section{References}

[1] D. Stöver, C. Funke, J. Mater. Process. Technol. 92-93 (1999) 195-202.

[2] W. A. Nelson, R. M. Orenstein, J. Therm. Spray Technol. 6(2) (1997) 176-180.

[3] A. G. Evans, D. R. Clarke, C. G. Levi, J. Eur. Ceram. Soc. 28 (2008) $1405-1419$. 
[4] R. Vassen, A. Stuke, D. Stöver, J. Therm. Spray Technol. 18(2) (2008) 181-186.

[5] R. Vassen, M. O. Jarligo, T. Steinke, D. E. Mack, D. Stöver, Surf. Coat. Technol. 205 (2010) 938-942.

[6] X. Q. Cao, R. Vassen, D. Stoever, J. Eur. Ceram. Soc. 24 (2004) 1-10.

[7] M. Belmonte, Adv. Eng. Mater. 8 (2006) 693-703.

[8] C. G. Levi, Curr. Opin. Solid State Mater. Sci. 8 (2004) 77-91.

[9] C. Wagner, Z. Phys. Chem. B21 (1933) 25-41.

[10] W. Quadakkers, D. Naumenko, E. Wessel, V. Kochubey, L. Singheiser, Oxid. Met. 61 (2004) 17-37.

[11] K. Ma, J. Schoenung, Surf. Coat. Technol. 205 (2010) 2273-2280.

[12] D. Achar, R. Munoz-Arroyo, L. Singheiser, W. Quadakkers, Surf. Coat. Technol. 187 (2004) 272-283.

[13] B. Baufeld, M. Schmücker, Surf. Coat. Technol. 199 (2005) 49-56.

[14] H. Evans, M. Taylor, Proc. IMechE 220 (2006) 1-10.

[15] P. Niranatlumpong, C. Ponton, H. Evans, Oxid. Met. 53 (2000) 241-258.

[16] D. Renusch, M. Schorr, M. Schütze, Mater. Corr. 59 (2008) 547-555.

[17] R. Mévrel, Mater. Sci. Eng., A 120 (1989) 13-24. 
[18] M. D. Ferdinando, A. Fossati, A. Lavacchi, U. Bardi, F. Borgioli, C. Borri, C. Giolli, A. Scrivani, Surf. Coat. Technol. 204 (2010) 24992503.

[19] W. Brandl, H. Grabke, D. Toma, J. Kruger, Surf. Coat. Technol. 86-87 (1996) 41-47.

[20] W. Chen, X. Wu, B. Marple, R. Lima, P. Patnaik, Surf. Coat. Technol. 202 (2008) 3787-3796.

[21] H. Brodin, Failure of thermal barrier coatings under thermal and mechanical fatigue loading: Microstructural observations and modelling aspects, Ph.D. thesis, Linköpings universitet, 2004.

[22] H. Echsler, V. Shemet, M. Schütze, L. Singheiser, W. J. Quadakkers, J. Mater. Sci. 41 (2006) 1047-1058.

[23] W. R. Chen, X. Wu, B. R. Marple, P. C. Patnaik, Surf. Coat. Technol. 197 (2005) 109-115.

[24] M. Jinnestrand, S. Sjöström, Surf. Coat. Technol. 135 (2001) 188-195.

[25] H. Brodin, R. Eriksson, S. Johansson, S. Sjöström, in: Ceramic Engineering and Science Proceedings.

[26] O. Trunova, T. Beck, R. Herzog, R. W. Steinbrech, L. Singheiser, Surf. Coat. Technol. 202 (2008) 5027-5032.

[27] M. Hadad, G. Margot, P. Démarécaux, D. Chicot, J. Lesage, L. Rohr, S. Siegmann, Surf. Eng. 23 (2007) 279-283. 
[28] D. Chicot, P. Démarécaux, J. Lesage, Thin Solid Films 283 (1996) 151157.

[29] M. Arrigoni, S. Barradas, M. Braccini, M. Dupeux, M. Jeandin, M. Boustie, C. Bolis, L. Berthe, J. Adhes. Sci. Technol. 20(5) (2006) 471-487.

[30] D. Chicot, P. Araujo, N. Horny, A. Tricoteaux, J. Lesage, Surf. Coat. Technol. 200 (2005) 174-177.

[31] Q. Hongyu, Y. Xiaoguang, W. Yamei, Int. J. Fract. 157 (2009) 71-80.

[32] L. L. Shaw, B. Barber, E. H. Jordan, M. Gell, Scr. Mater. 39(10) (1998) 1427-1434.

[33] P. F. Zhao, C. A. Sun, X. Y. Zhu, F. L. Shang, C. J. Li, Surf. Coat. Technol. 204 (2010) 4066-4074.

[34] N. Markocsan, P. Nylén, J. Wigren, X.-H. Li, A. Tricoire, J. Therm. Spray Technol. 18(2) (2009) 201-208.

[35] C. Lima, J. Guilemany, Surf. Coat. Technol. 201 (2007) 4694-4701.

[36] S. Sadeghi-Fadaki, K. Zangeneh-Madar, Z. Valefi, Surf. Coat. Technol. 204 (2010) 2136-2141.

[37] A. N. Khan, J. Lu, H. Liao, Surf. Coat. Technol. 168 (2003) 291-299.

[38] D. Chicot, G. Duarte, A.Tricoteaux, B. Jorgowski, A. Leriche, J. Lesage, Mater. Sci. Eng., A 527 (2009) 65-76. 
[39] J. Lesage, M. H. Staia, D. Chicot, C. Godoy, P. E. V. D. Miranda, Thin Solid Films 377-378 (2000) 681-686.

[40] M. Gell, E. Jordan, K. Vaidyanathan, K. McCarron, B. Barber, Y.-H. Sohn, V. K. Tolpygo, Surf. Coat. Technol. 120-121 (1999) 53-60.

[41] M. Jinnestrand, Delamination in APS applied thermal barrier coatings: life modelling, Ph.D. thesis, Linköpings universitet, 2004.

[42] R. Vaßen, F. Cernushi, G. Rizzi, A. Scrivani, N. Markocsan, L. Östergren, A. Kloosterman, R. Mevrel, J. Feist, J. Nicholls, Adv. Eng. Mater. 10 (2008) 907-921.

[43] Y. Liu, C. Persson, J. Wigren, J. Therm. Spray Technol. 13(3) (2004) 415-424.

[44] ASTM Standard C633 Standard Test Method for Adhesion or Cohesion Strength of Thermal Spray Coatings, ASTM International, 2008.

[45] H. Evans, M. Taylor, Oxid. Met. 55 (2001) 17-34.

[46] J. A. Haynes, E. D. Rigney, M. K. Ferber, W. D. Porter, Surf. Coat. Technol. 86-87 (1996) 102-108.

[47] W. R. Chen, X. Wu, B. R. Marple, P. C. Patnaik, Surf. Coat. Technol. 201 (2006) 1074-1079.

[48] J. A. Haynes, M. K. Ferber, W. D. Porter, E. D. Rigney, Oxid. Met. 52 (1999) 31-76. 
[49] W. R. Chen, X. Wu, D. Dudzinski, P. C. Patnaik, Surf. Coat. Technol. 200 (2006) 5863-5868.

[50] A. Gil, V. Shemet, R. Vassen, M. Subanovic, J. Toscano, D. Neaumenko, L. Singheiser, W. J. Quadakkers, Surf. Coat. Technol. 201 (2006) 38243828.

[51] T. Patterson, A. Leon, B. Jayaraj, J. Liu, Y. H. Sohn, Surf. Coat. Technol. 203 (2008) 437-441.

[52] D. Chicot, G. Marot, P. Araujo, N. Horny, A. Tricoteaux, M. H. Staia, J. Lesage, Surf. Eng. 22(5) (2006) 390-398.

[53] P. Araujo, D. Chicot, M. Staia, J. Lesage, Surf. Eng. 21(1) (2005) 35-40.

[54] H. Mei, L. F. Cheng, Y. N. Liu, L. T. Zhang, Mater. Sci. Forum 654-656 (2010) 1924-1927. 
Table 1: Number of specimens used in the present study. The numbers in the fourth column refer to the number of specimens used for each heat treatment length.

\begin{tabular}{llll}
\hline heat treatment & treatment length & substrate thickness & $\begin{array}{l}\text { number of specimens used for ad- } \\
\text { hesion test and microscopy }\end{array}$ \\
\hline as-sprayed & - & $6.35 \mathrm{~mm}$ & adhesion: 4 , microscopy: 1 \\
isothermal & $1 \mathrm{~h}$ & $5 \mathrm{~mm}$ & adhesion: 3, microscopy: 1 \\
isothermal & $23,47,111,290 \mathrm{~h}$ & $6.35 \mathrm{~mm}$ & adhesion: 4, microscopy: 1 \\
TCF & $24,48,300$ cycles & $6.35 \mathrm{~mm}$ & adhesion: 4, microscopy: 1 \\
BRT & 300,1150 cycles & $5 \mathrm{~mm}$ & adhesion: 3, microscopy: 1 \\
\hline
\end{tabular}

Table 2: Fraction of black fracture and amount of residual top coat (TC), after adhesion

\begin{tabular}{|c|c|c|c|c|c|c|c|c|c|c|c|}
\hline \multirow{2}{*}{$\begin{array}{l}\text { heat treatment } \\
\text { treatment length }\end{array}$} & \multirow{2}{*}{ none } & \multicolumn{5}{|c|}{ isothermal oxidation, $\mathrm{h}$} & \multicolumn{3}{|c|}{ TCF, cycles } & \multicolumn{2}{|c|}{ BRT, cycles } \\
\hline & & 1 & 23 & 47 & 111 & 290 & 24 & 48 & 300 & 300 & 1150 \\
\hline black fracture, $\%$ & 18 & 3 & 0 & 4 & 3 & 2 & 0 & 0 & 15 & 7 & 15 \\
\hline residual $\mathrm{TC}, \mu \mathrm{m}$ & 42 & 40 & 90 & 70 & 64 & 105 & 73 & 67 & 45 & 44 & 36 \\
\hline
\end{tabular}




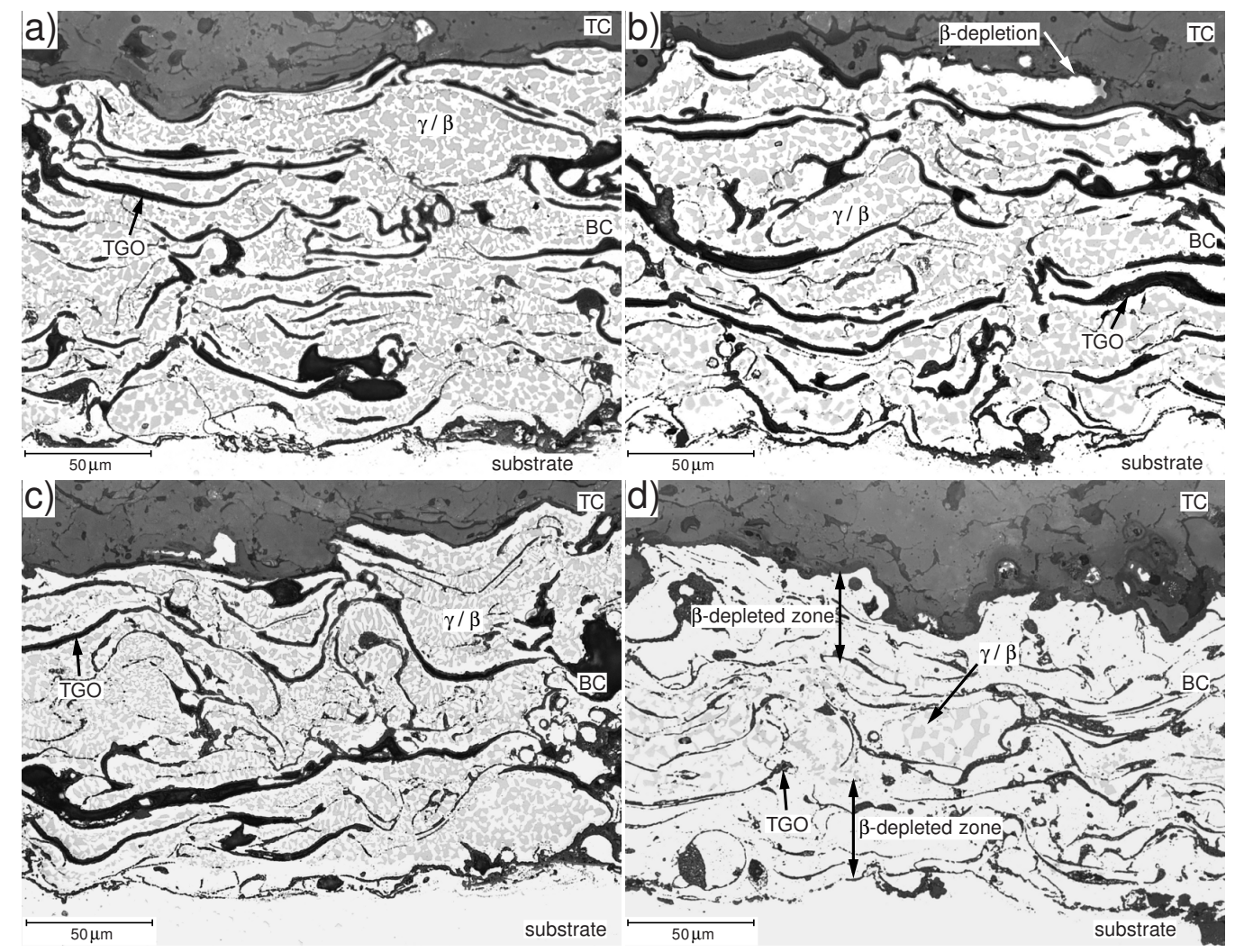

Figure 1: LOM micrographs of microstructural changes for BRT and isothermal oxidation at $\sim 1100^{\circ} \mathrm{C}$. a) BRT 300 cycles, b) BRT 1150 cycles, c) isothermal oxidation $1 \mathrm{~h}, \mathrm{~d}$ ) isothermal oxidation $23 \mathrm{~h}$. 


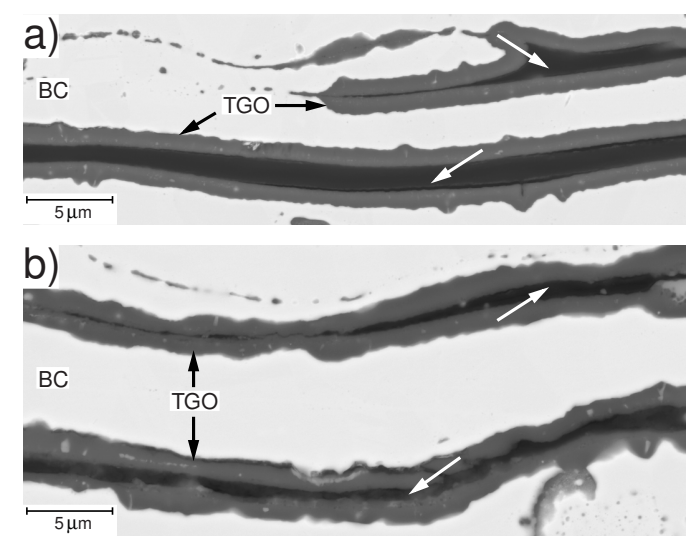

Figure 2: Backscatter electron images showing internal oxides in the bond coat, comparison between: a) Specimen subjected to BRT 1150 cycles, $1140^{\circ} \mathrm{C}$, arrows show inter-splat voids. b) Specimen subjected to TCF 24 cycles, $1100^{\circ} \mathrm{C}$, arrows show inter-splat voids.
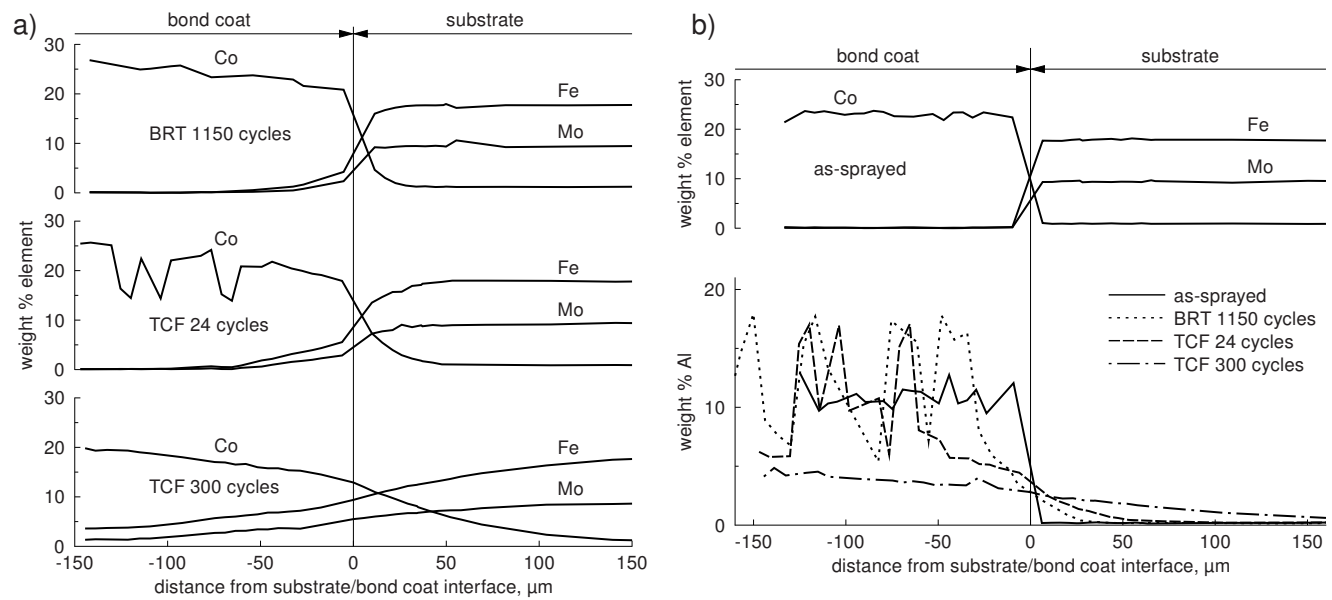

Figure 3: EDS measurement of composition in BC and substrate. a) Interdiffusion of Co, Fe and Mo between the $\mathrm{BC}$ and substrate for $\mathrm{BRT}$ and $\mathrm{TCF}, \sim 1100^{\circ} \mathrm{C}$. b) Composition of the as-sprayed condition as well as interdiffusion of $\mathrm{Al}$ for $\mathrm{BRT}$ and $\mathrm{TCF}, \sim 1100^{\circ} \mathrm{C}$. 


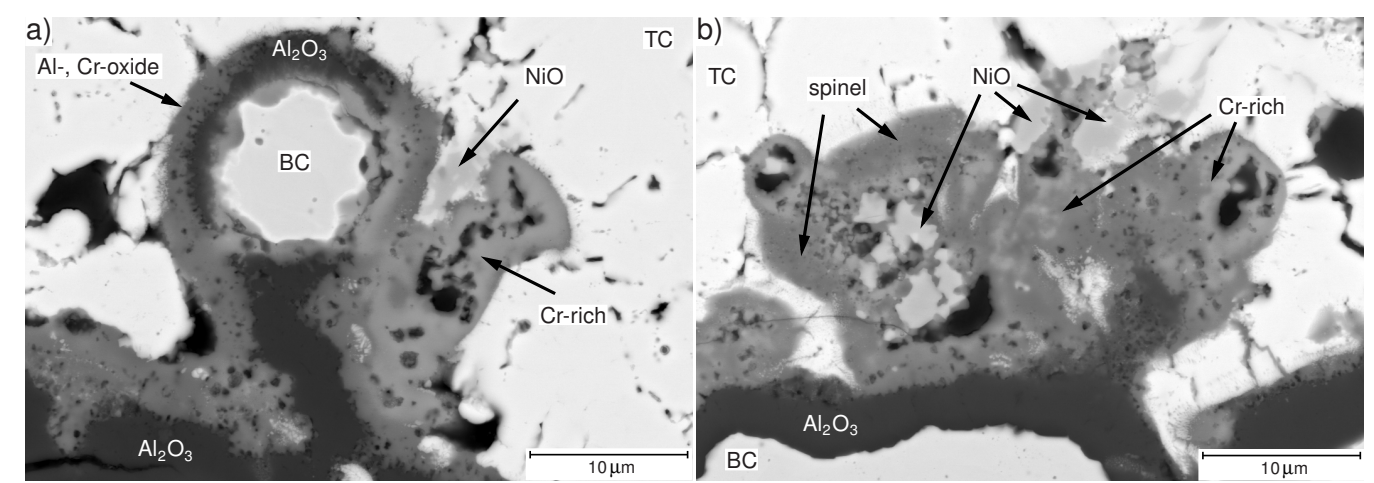

Figure 4: Backscatter electron images showing bulky oxide clusters, TCF 300 cycles, $1100^{\circ} \mathrm{C}$. a) Small metallic BC particle sticking out in the TC, oxidising rapidly forming an oxide cluster. b) An oxide cluster with a core of $\mathrm{NiO}$.
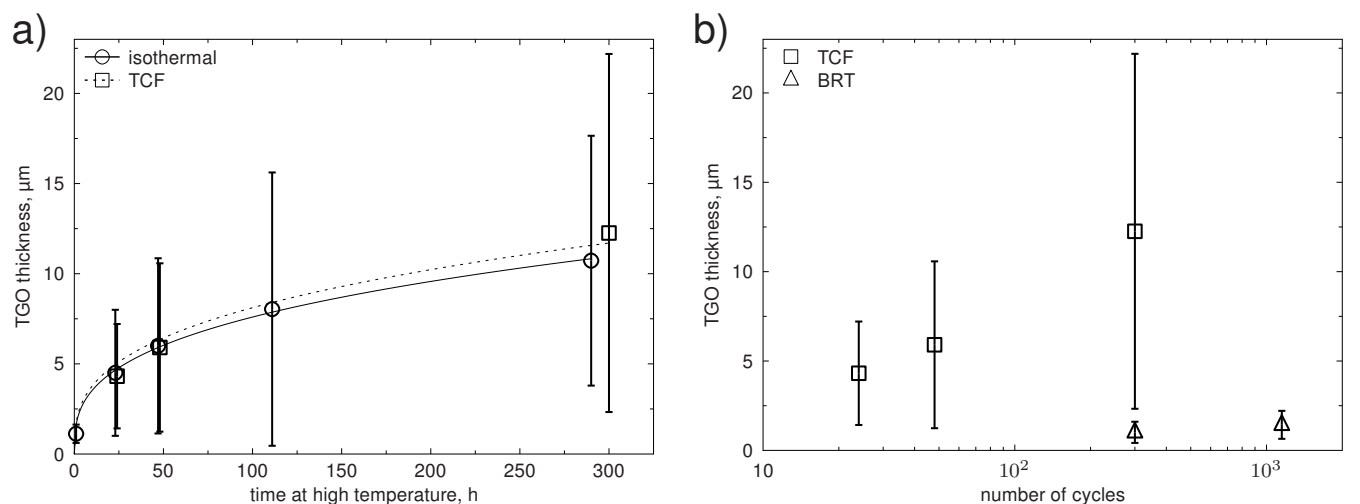

Figure 5: Interface TGO thickness as function of heat treatment length; the error bars show one standard deviation. a) Comparison between isothermal heat treatment and TCF, $1100^{\circ} \mathrm{C}$, (high temperature exposure for TCF have been calculated as dwell time $\times$ number of cycles). Curve fits have been made with Eq. 1. b) Comparison of TGO growth for specimens subjected to $\mathrm{TCF}$ and $\mathrm{BRT}, \sim 1100^{\circ} \mathrm{C}$. 

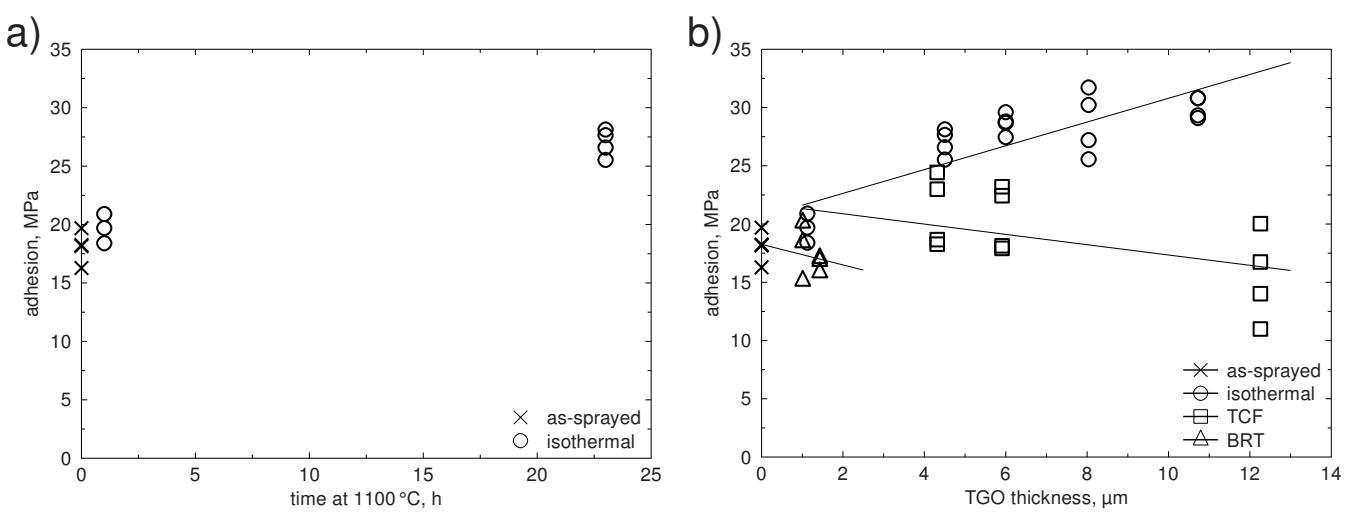

Figure 6: Change in adhesion with heat treatment. a) Adhesion for short-time isothermal oxidation, $1100^{\circ} \mathrm{C}$. b) Adhesion as function of TGO thickness for isothermal oxidation, $\mathrm{TCF}$ and $\mathrm{BRT}, \sim 1100^{\circ} \mathrm{C}$. The lines are linear least square fits to the mean values of the data.

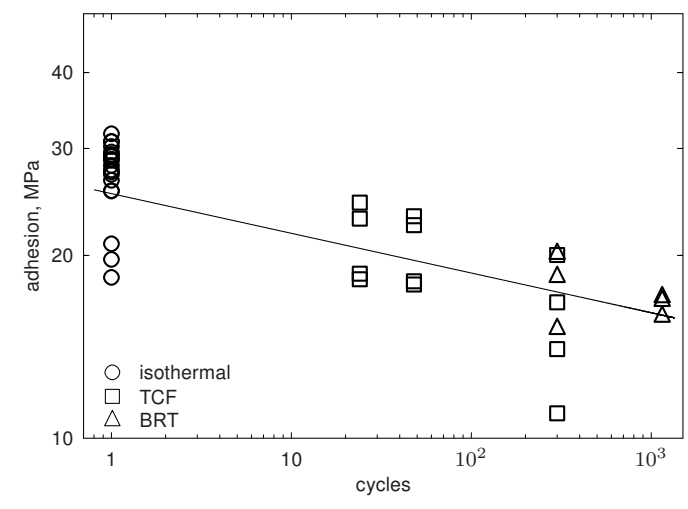

Figure 7: Adhesion as function of cycles. Data for specimens subjected to isothermal oxidation 1-290 h, TCF $24-300$ cycles and BRT 300 and 1150 cycles, $\sim 1100^{\circ} \mathrm{C}$. The line is a linear least square fit to the data. 


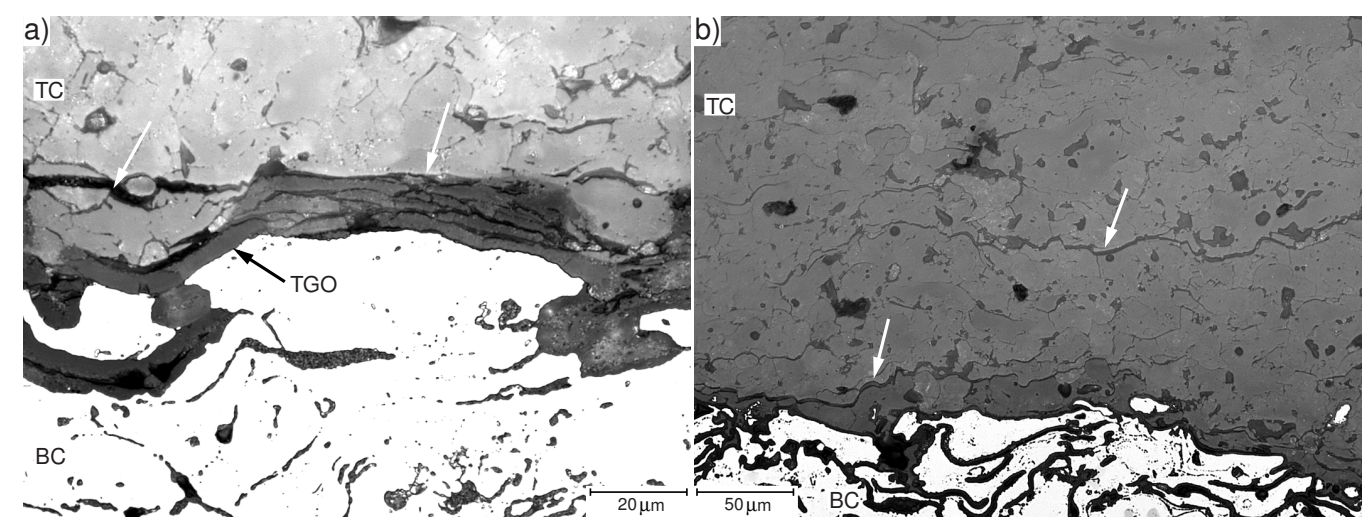

Figure 8: Damage due to thermal cycling in specimens subjected to TCF and BRT $1100^{\circ} \mathrm{C}$, LOM micrographs. a) Extensive cracking (layering) of TGO and the consequently damaged nearby TC, TCF 300 cycles. b) Modest inter-splat delamination in TC. Specimen subjected to 1150 cycles BRT.

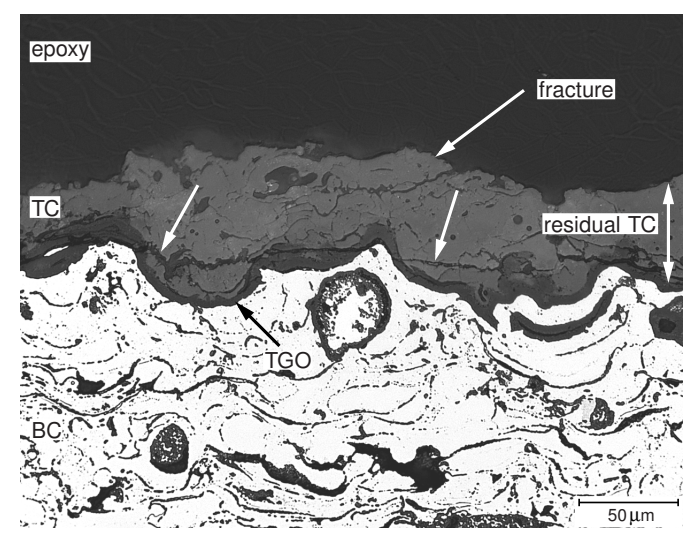

Figure 9: Fracture in adhesion tested specimen subjected to TCF 300 cycles $1100^{\circ} \mathrm{C}, \mathrm{LOM}$ micrographs. Fracture has occurred in the TC despite extensive BC/TC interface damage, (marked by the two arrows). 

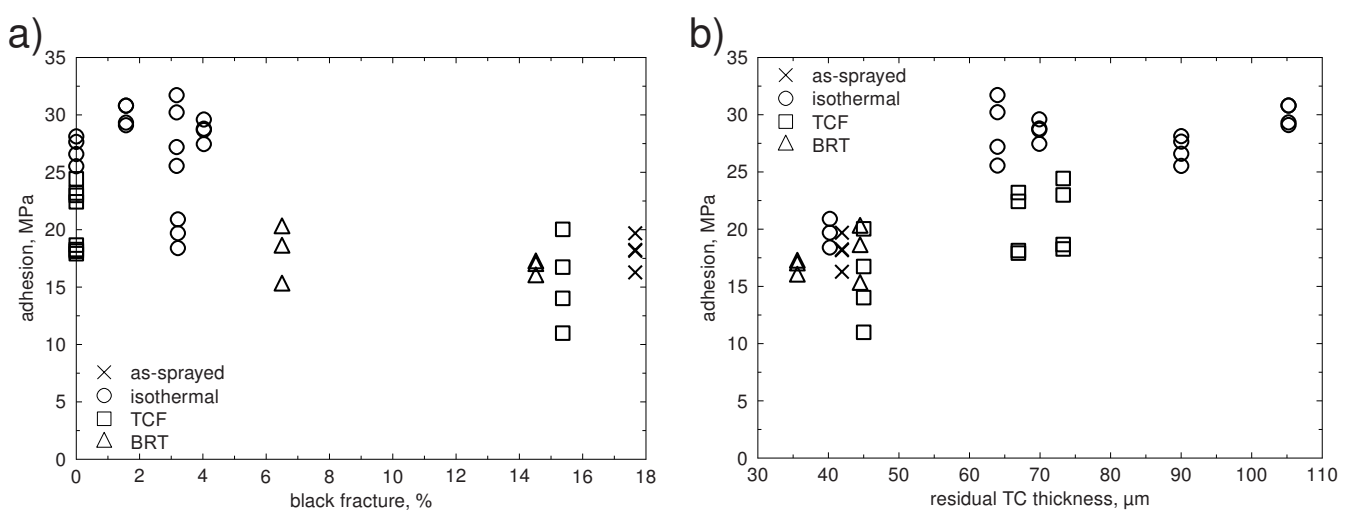

Figure 10: Fracture characteristics for specimens subjected to isothermal oxidation 1$290 \mathrm{~h}$, TCF $24-300$ cycles and BRT 300 and 1150 cycles, $\sim 1100^{\circ} \mathrm{C}$. a) Adhesion plotted versus fraction of black fracture, b) Adhesion as function of residual TC thickness. 